\title{
Medios de solución de conflictos, herramienta para la construcción del acceso a la justicia ${ }^{1}$
}

\author{
Means of conflict resolution, tool for building access to justice
}

\author{
Francisco, Enríquez-Chávez ${ }^{2}$ \\ (Dhttps://orcid.org/0000-0002-0291-1903 \\ Universidad de Guadalajara, México \\ https://doi.org/10.29105/pgc7.13-2
}

\author{
Marco Antonio, Santana-Campas ${ }^{3}$ \\ (iD)https://orcid.org/0000-0002-6750-2713 \\ Universidad de Guadalajara, México
}

\section{RESUMEN}

Los medios de solución de conflictos son una realidad desde hace años en México, pero no se ha logrado llegar a todos los sectores de la población obstaculizando el acceso a la justicia y por ende no se logra en totalidad la participación ciudadana para una construcción de la cultura de la paz. Objetivo: Describir las afectaciones a los trabajadores por demora en los juicios laborales y la no aplicación de manera eficaz de los medios de solución de conflictos en trabajadores del Sur de Jalisco. Método: investigación cualitativa, participantes: 30 personas que se encontraban dando seguimiento asuntos laborales ante la procuraduría del trabajo con sede en Zapotlán El Grande, Jalisco, México. Técnica de recolección de datos: entrevista semiestructurada exprofeso. Se encontraron principalmente afectaciones económicas, familiares y laborales principalmente. Los estudiosos del derecho deben utilizar el conocimiento en otras ciencias para advertir qué esconden los conflictos y solucionarlos empoderando a las partes para que éstos lo logren mediante el diálogo y empatía, sin necesidad de los formalismos del procedimiento judicial que dificulten el acceso a la justicia.

Palabras claves: Acceso a la justicia, derecho laboral, medios de solución de conflictos.

\section{ABSTRACT}

The means of conflict resolution have been a reality for years in Mexico, but it has not been possible to reach all sectors of the population by hindering access to justice and therefore citizen participation for a construction of the culture of peace is not fully achieved. Objective: To describe the affectations on workers by delay in labor trials and the effective non-implementation of the means of conflict resolution in workers in South Jalisco. Method: qualitative research, participants: 30 people who were following up labor issues before the labor attorney's office based in Zapotlán El Grande, Jalisco, Mexico. Data collection technique: ex profeso semi-structured interview. Mainly economic, family and labour impacts were found mainly. Law scholars should use knowledge in other sciences to warn what conflicts are hiding and to resolve them by empowering the parties to do so through dialogue and empathy, without the need for formalities in the judicial procedure that hinder access to justice.

Keywords: Access to justice, labor law, means of conflict resolution.

Recibido: 19 de Julio 2020 - Aceptado: 21 de Septiembre 2020

Cómo referenciar este artículo:

Enríquez-Chávez, F. \& Santana-Campas, M. A. (2021). Medios de solución de conflictos, herramienta para la construcción del acceso a la justicia. Revista Politica Globalidad y Ciudadanía, 41-65. Recuperado de http:// revpoliticas.uanl.mx/index.php/RPGyC/article/view/168. https://doi.org/10.29105/pgc7.13-2

\footnotetext{
1 Este artículo es producto del proyecto “Curso de Verano 2019 de la Maestría en Derecho del Centro Universitario del Sur”, financiado por los autores a través de la beca CONACYT, siendo el posgrado parte del Programa de Posgrados de Calidad. Iniciado en 2018 y finalizado en 2019. 2 Maestro en Derecho por la Universidad de Guadalajara. Email: francisco_ech@hotmail.com

3 Doctor en Psicología por la Universidad de Guadalajara, profesor de la Universidad Jesuita de Guadalajara y la Universidad de Guadalajara. Email: mascampas@gmail.com
} 


\section{1.- INTRODUCCION}

La paz no solo es la ausencia de guerra, es ser justo, hacer las cosas con orden, es tranquilidad, para Ruiz (2014), "la perturbación, la alteración del orden, que puede ser a través de la violencia entendida en su más amplia expresión, se constituyen enemigos de la paz” (p. 220)

Desde hace más de dos décadas, en México están reconocidos los métodos de solución de controversias, sin embargo, fue hasta la reforma constitucional de 2008 que empezaron a tomar más fuerza, empoderando a las partes para ellos mismos solucionar su problema mediante el diálogo, la empatía y la voluntad de resolverlo, al respecto, el criterio jurisprudencial menciona que:

Los mecanismos alternativos de solución de controversias, se rescata la idea de que son las partes las dueñas de su propio problema (litigio) y, por tanto, ellas son quienes deben decidir la forma de resolverlo, por lo que pueden optar por un catálogo amplio de posibilidades, en las que el proceso es una más (Tesis Aislada, 2013, registro 2004630).

Los conflictos siempre van a existir mientras existan las sociedades y más allá de verlo como la parte que se debe erradicar en las civilizaciones, se debe ver como la fuente de los acuerdos. El derecho nace justamente de los conflictos, de movimientos, de revoluciones. Actualmente las partes en conflicto no deben entenderse como dos entes que se obstruyen y se van a enfrentar y así evidentemente uno colisionar ante el derecho del otro. Además de ello, existen distintos obstáculos para acceder a la justicia, entre la demora de estos, la corrupción, la falta de recursos económicos para ostentar un juicio y malas asesorías judiciales.

Sin embargo, uno de los graves problemas de México en cuestión de justicia, es la corrupción o cultura de corrupción que hemos creado los ciudadanos; en el mundo del litigio, los abogados mantienen un esquema donde buscan justificar con la premisa errónea de apoyar a los servidores públicos que laboran para Poder Judicial, el pagar a los actuarios, a los auxiliares, secretarios o jueces para que las notificaciones se realicen con más rapidez, para que el oficio que necesitan esté 
primero que los demás, para que su expediente sea el de hasta arriba y los escritos que presenten sean los primeros en pasar y tengan una respuesta. Acciones que ya se ven como cotidianas, normalizadas e incluso como parte de la descripción de lo que es ser "buen litigante", se han convertido en un requisito obligatorio para que los servidores de los juzgados hagan su trabajo, ya que, de lo contrario, los juicios avanzarán a un paso más lento de lo que ya son por la carga laboral existente en los juzgados (Jasso, comunicación personal, 11 de diciembre de 2018).

Por lo que, apoyándose de la excesiva carga laboral en los juzgados o centros de impartición de justicia, los servidores públicos aprovechan para solicitar a los litigantes que, a cambio de dinero, sus asuntos serán los primeros en atenderse (Jasso, comunicación personal, 11 de diciembre de 2018). Es por esto que los Métodos Alternos de Solución de Conflictos deben tener un más impacto e importancia en la impartición de justicia en México, ya que con ellos, la posibilidad de terminar con los conflictos es un tiempo mínimo confrontado con el que se lleva en un procedimiento tradicional; además cuenta con otras ventajas como el empoderar a las partes en conflicto para que construyan la solución y con ello generar la sensación de satisfacción con el resultado, y haciendo a un lado la frustración de encontrarse con una sentencia donde uno gana y otro pierde.

En el derecho laboral, los trabajadores que prestan su servicios físicos o intelectuales han generado el derecho a una prestación y que se les niega su pago, pueden acudir a la Procuraduría de la Defensa del Trabajo, donde reciben asesoría sobre los derechos que se han ganado, y que previo a que iniciar un juicio, se debe primero concluir la etapa de conciliación, misma que será presidida por la misma Procuraduría como prestador de ese servicio; para lo cual se citará al patrón y al trabajador para asistir y procurar una solución (Agraz, comunicación personal, 18 de octubre de 2018)

Para evidenciar lo anterior, se realizó una entrevista a un funcionario de la Procuraduría de la Defensa del Trabajo, el mismo refirió que "los trabajadores son los que económicamente ostentan un juicio, por ejemplo, a sacar copias, trasladarse a Ciudad Guzmán si vive fuera, estar al pendiente del expediente, trasladar 
a testigos, pago de abogado si es particular" (Villalvazo, comunicación personal, 18 de octubre de 2018). De esta manera, cuando el trabajador acude a las oficinas de la Procuraduría, presenta su problema al Procurador, el cual tomando en consideración las particularidades del caso, puede enviar con entrega personal del mismo trabajador, un citatorio a su empleador para que ambos comparezcan a una cita conciliatoria, que debido a la carga de trabajo de esta dependencia, las conciliaciones se agendan entre una y dos semanas posteriores al de la emisión del citatorio, creando con esto un menoscabo al acceso y celeridad de la justicia.

\section{2.- MARCO TEÓRICO}

\section{Marco Jurídico}

La Constitución Política de los Estados Unidos Mexicanos (CPEUM) es clara al enunciar que ninguna persona podrá hacerse justicia por sí misma y que se tiene derecho a la administración de justicia por Tribunales creados para ello, de igual manera dispone que se preverán mecanismos alternos de solución de controversias (CPEUM, 1917, artículo 17). Dejando a un lado la idea de que únicamente se puede obtener justicia mediante la intervención de un Juez que decida por las partes y a través de un procedimiento prestablecido y riguroso.

Las autoridades jurisdiccionales fueron creadas para impartir justicia de conformidad a lo que establezca la ley. Justicia que de acuerdo con lo señalado en nuestra Carta Magna debe ser gratuita, pronta, imparcial y se debe resolver en los plazos que la ley señale para tal efecto y en los Tribunales previamente establecidos, es decir, la Constitución debe asegurar a los ciudadanos el acceso a la justicia y el Estado tiene la obligación de aminorar o eliminar los obstáculos que aseguren ese acceso a la justicia en los términos establecidos y con la mayor prontitud posible.

Si bien es cierto que, en los asuntos del orden civil, ya se encuentra establecido en el artículo 282 bis del Código de Procedimientos Civiles para el Estado de Jalisco, la conciliación, ésta no deja de ser parte dentro del procedimiento judicial, es entonces que antes de pensar en juzgados o tribunales, tanto los abogados como las personas deben considerar someter su conflicto a los medios de solución que 
no son judiciales.

\section{Procedimiento alterno}

Si lo que una persona está reclamando son alimentos a su pareja para su o sus hijos, habrá de acudir a un abogado para que realice este trámite ante el juzgado correspondiente y a cambio de los honorarios respectivos. Tendrá que pasar por las etapas procesales necesarias y el tiempo que tarde la autoridad en decretar una resolución, por lo que las partes estando conscientes de sus derechos, sus obligaciones y a través de los métodos de solución de conflictos, podrán llegar a un acuerdo y en pocas semanas haber resuelto la controversia.

En el caso laboral, si un empleado es separado de su fuente de trabajo, se estará despojando de su medio de subsistencia, para pagar alimentación, salud, vestido, educación, etcétera, para él y sus dependientes económicos, por lo que alargarlos, provoca un estado de indefensión al trabajador por no contar con lo indispensable para su subsistencia

Al respecto Castillo dice:

El Estado debe contar con una normatividad que incorpore disposiciones sustantivas y procedimentales que establezcan pautas y principios justos y en condiciones de igualdad. Así mismo, debe procurar para que los despachos judiciales sean suficientes para atender la demanda de conflictividad, que los procedimientos no sigan siendo cadenas tortuosas, demoradas y costosas para las partes, de manera que surja como regla general confianza en la norma y en la administración de justicia (Castillo, 2018, p. 6).

El acceso a la justicia no exclusivamente significa que un Juez solucione un conflicto o controversia entre dos o más personas mediante un procedimiento preestablecido y emitiendo una sentencia, el término justicia, también se refiere a aquello que permite salvaguardar un derecho y lograr una solución sin necesidad de acudir a tribunales. Así pues, los medios alternos de solución de conflictos deberían tomar mayor partida en la justicia de nuestro país. En el derecho laboral 
que es desde hace varias décadas quien ha solucionado conflictos con medios alternos a través de la conciliación (Natividad, 2015).

Hernández, (2010) describe los pasos o las formas para desarrollar una audiencia conciliatoria, donde las partes se someten al procedimiento ante un tercero llamado conciliador; el conciliador debe ser un profesional que cuente con las herramientas y especializaciones necesarias para propiciar el diálogo entre las partes, fomentando comunicación asertiva y lograr que se expresen el sentir, generando empatía para que las partes entiendan las necesidades del otro, donde ellos mismos aporten las ideas que lleven a encontrar la solución del conflicto con ayuda del conciliador, quien habiendo escuchado el problema visto desde ambas partes, propone la forma en que termine la controversia, plasmando todo lo anterior en un convenio y que este tenga la calidad de sentencia ejecutoriada o en el caso de la materia laboral, la de laudo.

De acuerdo con el artículo 530 fracción III de la Ley Federal del Trabajo, la Procuraduría de la Defensa del Trabajo, dentro de sus funciones propondrá a las partes soluciones para solucionar las controversias, autorizando en actas estos arreglos, es decir, la Procuraduría está facultada para hacer uso de los métodos alternos de solución de conflictos, a través de la conciliación para evitar los juicios laborales (Ley Federal del Trabajo, 1970, artículo, 530). En estos casos, el Procurador auxiliar fungirá como prestador del servicio, es decir, será el conciliador, sin embargo, el servicio está limitado a quienes son trabajadores, si una persona acude con el carácter de patrón, no podrá solicitar cita para una audiencia conciliatoria, si bien este patrón puede asesorarse con el representante patronal de las Juntas de Conciliación y Arbitraje, se limita a justamente eso, la explicación de los derechos del trabajador y las obligaciones del patrón con su empleado, sin la posibilidad de solicitar la celebración de la sesión de conciliación.

Además de lo anterior, el prestador de servicio debe ser imparcial y las reuniones, a pesar de ello, el Procurador, por su misma naturaleza y como su propio nombre lo dice "Defensa del Trabajo", tiene una inclinación por defender al trabajador, tan es así que, si no se llega a una solución conciliatoria, el Procurador podrá par- 
ticipar en el juicio laboral como defensor de oficio del trabajador.

\section{Procedimiento conciliatorio Procuraduría de la Defensa del Trabajo}

En el Reglamento de la Procuraduría Federal de la Defensa del Trabajo (2014) en su capítulo séptimo describe los procedimientos ante las Procuradurías, el cual es de la siguiente manera:

I) El trabajador deberá acudir a las oficinas de la Procuraduría que le corresponda, donde se asesorará sobre el conflicto laboral que exponga, y en caso de ser procedente, el Procurador podrá girar citatorio tanto al trabajador como a la parte patronal para asistir a la audiencia conciliatoria.

II) El trabajador y el patrón asisten a la cita: se informa el motivo de la misma y se propondrá soluciones para así evitar un juicio. Si se llega a ese arreglo, se redactan las actas correspondientes y el problema finaliza.

III) El trabajador no acude a la cita: se redacta un acta de incomparecencia del trabajador y al ser el interesado, se considera que no tiene interés legal por el asunto.

IV) El patrón no acude a la cita: se redacta un acta de incomparecencia de la fuente de trabajo y si no hay riesgo respecto de la prescripción de la acción, manda un segundo y último citatorio, el cual tiene que hacer llegar el trabajador (de igual forma que el primero).

V) Las partes se presentan a la cita (primera o segunda): no llegan a un arreglo, se redacta el acta donde se plasma que asistieron ambas partes, pero no fue posible conseguir el arreglo.

El Procurador propone al trabajador iniciar el juicio en contra del patrón.

El trabajador podrá demandar contratando el abogado de su elección, sin embargo, deberá pagar honorarios y otros gastos como el de traslado del abogado si así fuera el caso.

Derivado de lo anterior, La Rosa (2008) comenta 
El asunto a tratar radica en si en condiciones de desigualdad real, el ciudadano común y corriente tiene la posibilidad de acceder a alguno de los mecanismos existentes permitiendo legítimamente determinar derechos y resolver su conflicto, con resultados que tengan validez ante terceros. Lo cual debiera significar que no solamente importen las vías judiciales sino aquellas otras formas que la Constitución Política y la legislación ordinaria reconoce (p. 105).

De lo anterior la importancia que se debe dar a los medios de solución de conflictos y no tenerlos únicamente como alternativa, sino que sea la primera vía para resolver conflictos, otorgando el poder a las mismas partes de decidir cómo va a terminar el conflicto y teniendo la certeza de que su decisión tendrá la fuerza para hacerla valer en caso de incumplimiento. Al respecto, Bonilla menciona que:

Entre los obstáculos que impiden o dificultan el acceso a los tribunales, sin duda está el de su fallida ubicación o delimitación geográfica. Un tribunal mal ubicado o que ejerce jurisdicción sobre un territorio no correctamente delimitado, ocasiona que los justiciables eroguen más gastos en la tramitación de sus asuntos, que los procesos sean más largos, que sus cargas de trabajo no sean proporcionales respecto a las de otros tribunales, que la comunidad se inconforme y que, incluso, los individuos opten por no acudir a él para resolver las controversias jurídicas. (Bonilla, 2017, p. 266)

Así pues, que la garantía de tutela judicial deberá prever los obstáculos en cada territorio para que los ciudadanos accedan a la justicia, como lo menciona Bonilla, que:

Puede sostenerse, en términos jurídicos, la existencia del principio de que los tribunales deben estar ubicados en los sitios de más fácil acceso para los justiciables, conforme al texto de los artículos 1o., 13, 14 y 17 de la Constitución Política de los Estados Unidos Mexicanos. En estos preceptos hay directrices sobre la creación de tribunales y sobre la asignación de competencia territorial (Bonilla, 2017, p. 263). 
En el caso de las Juntas de Conciliación, el actuario no tiene presupuesto para trasladarse y realizar los emplazamientos y la fuente de trabajo que está en un municipio lejano (más de 50 kilómetros de donde se encuentra la autoridad laboral), el trabajador será quien solvente esos gastos, que al incluyen la gasolina del actuario, sus alimentos o en algunos casos las propinas que éstos exigen. Además de lo anterior, y considerando que

El procedimiento para interponer una queja como trabajador consta de seis pasos, de acuerdo con la Ley Federal del Trabajo: presentación de la demanda, notificación al patrón de que es demandando, celebración de audiencia de conciliación, desahogo de pruebas, formulación y aprobación de la demanda y resolución. Este proceso debe llevar entre dos o tres meses (Guzmán, comunicado personal 18 de marzo de 2017).

En este sentido, Ovalle (1996), refiere que más allá de las etapas y tiempos, se debe hacer una interpretación más amplia del proceso y acceso a la justicia a los trabajadores, y argumenta que:

El derecho de acceso a la justicia no se limita a consignar la posibilidad meramente formal de acudir ante los tribunales para formular pretensiones o defenderse de ellas; sino que implica, además, el deber del Estado de remover todos aquellos obstáculos materiales que impidan o dificulten el acceso efectivo de las personas a los tribunales (Ovalle, 1996, p. 290).

Además, pueden existir más obstáculos que prolongan los juicios y el acceso a la justicia, "en la realidad es muy distinto, puesto que los encargados de notificar en ocasiones no encuentran los domicilios o los patrones modifican su razón social. Estos son los motivos que suelen alargar la realización de las audiencias y como consecuencia la resolución de los conflictos" (Material transmitido por el Servicio Sindicado el pasado 18 de marzo de 2017). La notificación es difícil porque en algunos casos es complicado encontrar a las personas que ha de emplazarse; o por otro lado el buscarlos para la ejecución de las sentencias, cuando se busca para embargar, no se encuentra a la persona o ya no hay bienes en el domicilio.

Cuando un trabajador ha conseguido que se termine el juicio, donde fue debida- 
mente notificado y se desahogaron todas las audiencias, se dictó laudo, y aunque sea favorable para el trabajador, se tiene que ejecutar, pudiendo también llevar mucho tiempo para que se efectúe, "el problema es ejecutar la resolución, ya sea obtener la reinstalación o el pago de salarios caídos. El tiempo que pueden tardar los patrones en atender esas resoluciones puede aumentar el proceso a más del doble" (Material transmitido por el Servicio Sindicado el pasado 18 de marzo, 2017).

De lo anterior se desprende y se coincide que las instituciones de conciliación y mediadoras pueden y deben ser instrumentos para la construcción de paz social y promotoras de la participación ciudadana, considerando que al llegar a un acuerdo mediante la mediación la expectativa de cumplimiento de los acuerdos es alta puesto que se realiza en acuerdo de partes, además se tiene el veneficio de no judicializar los procesos y por ende la celeridad de los procesos y acceso a la justicia (De villa, 2012; García, 2007).

Esto toma especial relevancia ante las transformaciones sociales en las últimas décadas y en especial en el mundo del trabajo, donde debe garantizarse el acceso a la justicia sin restricciones en igual de condiciones sin importar el nivel, cultural, económico, escolar, etcétera, es decir, a toda persona por igual se le debe garantizar un proceso y sentencias apegadas a derecho y en condiciones de igualdad (Maraniello, 2008; Padrón 2018). Siendo esto uno de los fines de la mediación y conciliación.

\section{Reforma laboral}

De conformidad con el artículo 590-E de la nueva reforma laboral (Oficio D.G.P.L. 64-II-7-685, 2019), “corresponde a los Centros de Mediación realizar la función conciliadora", el cual concatenado con el artículo 684-B de la Ley Reformada (Oficio D.G.P.L. 64-II-7-685, 2019), establece que "los trabajadores y patrones deberán asistir al Centro de Conciliación correspondiente para solicitar el inicio del procedimiento de conciliación" siendo que con la Ley actual, el patrón no puede solicitar esta audiencia y solo el trabajador la consigue solicitarla medi- 
ante la Procuraduría de la Defensa del Trabajo, dejando en posibilidad del patrón el solucionar el problema antes de que llegue a juicio. Además, la función del Procurador de la Defensa del Trabajo ya no será la de conciliar sino únicamente la de velar por los derechos del trabajador, pudiendo asistirlo en la audiencia conciliatoria.

Una vez solicitada y notificada la audiencia conciliatoria previa al juicio y en caso de que solo en solicitante comparezca a la misma, el Centro de Conciliación levantará constancia de haber agotado la etapa de conciliación prejudicial obligatoria, artículo 684-E fracción X (Oficio D.G.P.L. 64-II-7-685, 2019), a diferencia del procedimiento actual, donde la Procuraduría manda citar a la parte patronal mediante documento que el mismo trabajador por sus propios medios debe entregar y en el supuesto de inasistencia de la parte patronal, podrá enviar un segundo citatorio para llevar a cabo la audiencia, alargando más el proceso y saturando más la agenda de la misma Procuraduría.

En el nuevo sistema laboral (Oficio D.G.P.L. 64-II-7-685, 2019), en el artículo 684-G, toma mayor seriedad a los métodos alternos al desvincular esta función dentro del procedimiento, estableciendo los requisitos y la forma en que se elegirán las personas que realicen esa labor, fomentando su adecuada aplicación y por lo tanto obteniendo mejores resultados, y de esta manera permitiendo que el tribunal laboral se enfoque únicamente en la función jurisdiccional. Dado lo anterior es que en esta investigación se planteó como objetivo principal: Describir las afectaciones a los trabajadores por demora en los juicios laborales y la no aplicación de manera eficaz de los medios de solución de conflictos en trabajadores del Sur de Jalisco.

\section{3.- MÉTODO}

El artículo "Medios de solución de conflictos, herramienta para la construcción del acceso a la justicia". Nace de las actividades de verano de la Maestría en Derecho del Centro Universitario del Sur de la Universidad de Guadalajara, que se encuentra dentro de los Posgrados de Calidad del CONACYT. Buscó proyectar 
datos acerca del acceso a la justicia y el papel que los métodos alternos de solución de conflictos juegan en este. Dado que se buscó describir las afectaciones económicas, familiares y laborales desde la perspectiva de los trabajadores es que se tomó la decisión de optar por la metodología cualitativa.

\section{Diseño}

En esta investigación no existió manipulación de variables, estas fueron observadas en su contexto natural, es por esto por lo que es una investigación no experimental, de tipo cualitativa descriptiva y transversal.

\section{Participantes}

Está se tomó de los trabajadores que acudieron durante el mes de abril a la Procuraduría de la Defensa del Trabajo en Zapotlán el Grande, Jalisco a fin de recibir asesoría o estaban llevando un juicio, por tanto, la selección de la muestra fue no probabilística y por conveniencia, es decir, el investigador principal, durante el periodo antes mencionado acudía a las oficinas de la Procuraduría para entrevistar a las personas. La muestra final fue de 30 trabajadores que aceptaron realizar la entrevista. La Procuraduría de la Defensa del Trabajo con sede en Zapotlán el Grande, Jalisco, atiende a 28 municipios de la Zona sur de Jalisco y representa una superficie total aproximada de $5,650.60 \mathrm{~km} 2$

\section{Instrumentos}

Una vez que se estableció el objetivo y tipo de investigación, se eligió la técnica de recolección de datos la entrevista semiestructurada, está se diseñó exprofeso para identificar las variables sociodemográficas, percepción de la autoridad, motivo por el acude al servicio y estado procesal en caso de haber iniciado juicio. Este consistió en 28 reactivos, el cual contuvo preguntas abiertas y cerradas con el objetivo de conocer la percepción desde los trabajadores sobre las variables de estudio.

Al tratarse de una investigación cualitativa y de percepción de una población y contexto específicos, que no se busca generalizar los datos, sino que estos fueran 
el detonador de reflexiones en torno a la mediación y solución de conflictos, no resultó necesario realizar las pruebas métricas del cuestionario.

\section{Procedimientos}

Una vez que se diseñó la investigación se solicitó el aval de la Junta Académica de la Maestría en Derecho del Centro Universitario del Sur de la Universidad de Guadalajara, posterior se solicitó el permiso y apoyo del responsable de la Procuraduría de la Defensa del Trabajo en Zapotlán el Grande, Jalisco, una vez que se obtuvieron los permisos necesarios el investigador principal acudió a las instalaciones de la Procuraduría de la Defensa del Trabajo en Ciudad Guzmán, Jalisco, México, el periodo de aplicación fue del 16 al 23 de abril de 2019.

Durante el periodo antes mencionado y en las instalaciones de la Procuraduría, se realizó contacto con los trabajadores que acudieron a servicio a dicha institución, al abordarlos se les explicó el objetivo de la investigación y se les invitaba a participar, a los que aceptaron se les dio a firmar el consentimiento informado y se procedía con la encuesta.

Las encuestas se realizaron en un espacio donde garantizaba la confidencialidad de esta, asimismo, se realizó cara a cara y fue audio grabada, la muestra final fue de 30 trabajadores. Una vez que su tuvieron las 30 entrevistas, las respuestas a preguntas abiertas fueron transcritas a procesador de texto para realizar análisis de contenido, y las respuestas a las preguntas cerradas se capturaron en una base de datos para realizar análisis estadísticos descriptivos.

Ética: Esta investigación se sometió a evaluación a la Junta Académica de la Maestría en Derecho, órgano colegiado encargado de vigilar la calidad de la investigación, el respeto a los derechos humanos en la investigación y garantía que las investigaciones respeten y garanticen los principios de la Declaración de Helsinki y las Recomendaciones para la Ciencia y los Investigadores científicos La Organización de las Naciones Unidas para la Educación, las Ciencias y la Cultura (UNESCO). 


\section{4.- CONCLUSIONES}

El objetivo principal de esta investigación fue el describir las afectaciones a los trabajadores por demora en los juicios laborales y la no aplicación de manera eficaz de los medios de solución de conflictos en trabajadores del Sur de Jalisco. Y como ya se mencionó en el apartado correspondiente, participaron 30 trabajadores que acudieron a las instalaciones de la Procuraduría de la Defensa del Trabajo en Ciudad Guzmán, Jalisco, México, a solicitar asesoría legal respecto a su situación laboral, de los cuales, tenían una edad de entre los 18 a los 65 años, 73 \% de los encuestados fueron hombres y $27 \%$ mujeres, del asunto por el que acudieron, 4 participantes tuvieron un accidente de trabajo, 7 renunciaron a su empleo y se les negó el finiquito y 19 fueron despedidos; el $57 \%$ de los encuestados vivían en pareja (casados o unión libre), $37 \%$ solteros y $6 \%$ eran viudos o divorciados.

De los trabajadores encuestados, el 53.3\% refirió era el principal sustento de la familia y el $47 \%$ reporto que no era el principal sustento económico familiar. En cuanto a los ingresos mensuales, los encuestados reportaron que el $97 \%$ percibía un salario entre $\$ 1,000$ y $\$ 10,000$ pesos mensuales; y solo $3.3 \%$ contaba con un salario entre $\$ 10,001$ y $\$ 15,000$. En la Tabla 1 se presentan los resultados sobre las afectaciones percibidas por los trabajadores al estar llevando un proceso en la instancia correspondiente.

Tabla 1: Afectaciones principales durante el proceso

\begin{tabular}{lccccc} 
& \multicolumn{2}{c}{ Si } & & No & \\
& $n$ & $\%$ & 0 & 0 \\
Económico & 14 & 47 & 0 & 0 \\
Familiar & 1 & 3 & 0 & 0 \\
Perdida de empelo & 4 & 13 & 0 & 0 \\
No ha detectado & 5 & 17 & 0 & 0 \\
No contesto & 6 & 20 &
\end{tabular}

$n$ se refiere al número de muestra $\mathrm{y} \%$ al porcentaje absoluto

Fuente: Elaboración propia, (2020). 
La percepción de las consecuencias que los encuestados al estar en el proceso son: $17 \%$ no ha detectado consecuencias, $20 \%$ no fue su deseo responder, $47 \%$ tuvieron daño económico, $3 \%$ descuidó asuntos familiares y $13 \%$ se encontraron con la pérdida de empleo al solicitar constantes permisos para asistir a audiencias. En la tabla 2 se describen las respuestas a la pregunta de ¿Cuántas veces ha acudido a la procuraduría del trabajo?

Tabla 2: ¿Cuántas veces ha acudido a la procuraduría del trabajo?

\begin{tabular}{lcc} 
& $n$ & $\%$ \\
\hline Primera vez & 16 & 53 \\
\hline Segunda vez & 5 & 17 \\
Tercera vez & 6 & 20 \\
Cuarta vez & 3 & 10
\end{tabular}

$n$ se refiere al número de muestra $\mathrm{y} \%$ al porcentaje absoluto

Fuente: Elaboración propia, (2020).

De los participantes, el $47 \%$ de ellos habían viajado en dos o más ocasiones a la autoridad sin que en ninguno de los casos se haya solucionado el problema por el que acudieron. Asimismo, refirieron que los gastos económicos invertidos en traslados, asesorías y viáticos son recursos económicos que hubieras sido invertidos en alimentación de la familia, pago de deudas, reta de casa entre otros. Anudo a lo anterior, el $60 \%$ de los encuestados refirieron que tenían de 2 a 4 dependientes económicos y el $66.6 \%$ aun no encontraba un nuevo empleo por lo que en ocasiones se han visto en la necesidad de pedir préstamo para poder costear los gastos de los traslados a la procuraduría del trabajo.

De los resultados anteriores se puede inferir que el perder el empleo no solo se ve afectado su ingreso familiar, sino que, además el llevar un proceso para hacer valer sus derechos también les genera un costo económico y familiar, cuando el acceso a la justicia es un derecho humano que se debe garantizar como medio para alcázar la paz y por ende el mejoramiento de la calidad de vida de los trabajadores. 


\section{Discusión}

Se tienen muchas ventajas al no judicializar las controversias y ventilar los problemas en juicio, además de la rapidez y la economía es de gran importancia la finalidad, que se solucione el conflicto, De Villa menciona

Una de las grandes ventajas de la mediación es que, en caso de llegar a un acuerdo, éste es totalmente construido por los mediados, por lo que el grado de cumplimiento voluntario de los convenios es muy alto. Y en caso de incumplimiento, que se da en la minoría de las veces, se puede solicitar la ejecución ante un juez (De Villa, 2012, p.22).

Los medios alternos conjugan conocimientos de distintas profesiones, mediante una buena comunicación, orientando a las partes a construir la solución, entendiendo las conductas y conociendo los alcances jurídicos de las decisiones para que los acuerdos sean idóneos y legales, así como desarrollando habilidades de negociación. Es por ello por lo que Velásquez (2004) define "La conciliación ha sido definida como un mecanismo ágil de solución de conflictos a través del cual dos o más personas gestionan por sí mismas la solución de sus diferencias, con ayuda de un tercero neutral y calificado" (p.108). Así pues, que es necesario que exista una verdadera y profunda capacitación para que el prestador realmente esté calificado y no solo encuentre un negocio en la conciliación.

Además de contar con reglas bien establecidas para llevar a cabo los medios de solución de conflictos, de la excelente preparación que deban tener los prestadores, la mediación también promueve que las personas se acerquen y decidan sobre sus conflictos, al respecto García (2007) dice

La institución mediadora, conceptuándola como un instrumento de paz social en apoyo a la familia y de los intereses superiores de los niños, con capacidad de promover la participación ciudadana en la administración de justicia, pero con un importante reconocimiento como servicio social especializado (pp.89-90).

La paz se genera mediante el diálogo, la empatía, comprendiendo al prójimo y 
siendo solidario; estas mismas características se necesitan para lograr resolver un conflicto sin judicializarlo. Un profesionista bien capacitado para lograr la comunicación entre las personas en conflicto podrá propiciar la solución al conflicto con la sensación de certeza que genera paz en las personas al saberse con el problema resuelto y sin que el derecho de alguno de ellos haya sido aplastado por el del otro.

Dado lo anterior, se infiere que, en la población de estudio para esta investigación, tiene dificultades para acceder a la justifica laboral, entre las dificultades se encontró la distancia entre su domicilio y la sede la procuraduría del trabajo, no contar con los recursos suficientes para traslados, viáticos, entre otros para acudir a las audiencias. Al respecto Maraniello (2008) considera que "no puede existir ningún tipo de restricciones al acceso a la justicia, ni sociales, ni culturales, ni económicas, donde todas las personas puedan obtener una sentencia en condiciones de igualdad. Todo ello como política económica del Estado" (p. 115). En este sentido, la Constitución Política de los Estados Unidos Mexicanos garantiza que se respeten los derechos fundamentales de las personas, donde uno de ellos es el de que se la justicia sea accesible, gratuita, pronta e imparcial; es por ello por lo que el Estado está obligado a ofrecer justicia a sus gobernados mediante tribunales, y se debe asegurar de reducir los obstáculos que entorpezcan el alcance de este derecho fundamental.

Los órganos encargados de la impartición de justicia se distribuyen por el Poder Judicial o en el caso de las Juntas de Conciliación y arbitraje, por el Poder Ejecutivo Estatal a través de la Secretaría del Trabajo y Previsión Social. El acceso que pueda dar el Estado a los gobernados a la justicia va relacionado con los medios de que disponga y las posibilidades físicas, por lo cual se deben tomar las medidas necesarias para erradicar en lo posible, los obstáculos que evitan que los ciudadanos hagan valer sus derechos, en este sentido, la distancia entre los domicilios de los trabajares y centralización de las procuradurías es uno de los principales obstáculos para acceder a la justicia de la muestra estudiada en esta investigación.

Hace falta mucho qué trabajar para poder tener condiciones justas para los tra- 
bajadores y las condiciones laborales para formar una vida digna, para Padrón (2018) "una de las consecuencias más evidentes y profundas de las transformaciones desde las últimas décadas del siglo XX, que definen al mundo del trabajo, es el aumento inusitado y sostenido de la desigualdad social" (p. 9).

Casal (2008) precisa en un sentido amplio que:

...el acceso a la justicia es un derecho consistente en la disponibilidad real de instrumentos judiciales o de otra índole previstos por el ordenamiento jurídico que permitan la protección de derechos o intereses o la resolución de conflictos, lo cual implica la posibilidad cierta de acudir a ante las instancias facultadas para cumplir esta función y de hallar en éstas, mediante el procedimiento debido, una solución jurídica a la situación planteada (p.133).

En el caso derecho del trabajo, se han establecido lugares determinados donde se encuentran las Juntas de Conciliación y Arbitraje donde se asesora y accionan los derechos por: renuncias, despidos justificados e injustificados, etcétera, se manejen en salida alterna o se ventilan las demandas. Esta autoridad ejerce su jurisdicción en veintiocho municipios para el caso del Sur de Jalisco, mismo en el que las condiciones de distancia del domicilio del trabajador, deja como resultado que los trabajadores opten por no asesorarse o no iniciar el juicio puesto que el adeudo generado por sus derechos laborales no baste para mantener el juicio. Márquez (2008) considera que la conciliación:

La conciliación no tiene en estricto sentido el carácter de actividad judicial ni da lugar a un proceso jurisdiccional, porque el conciliador, autoridad administrativa o judicial o particular, no intervienen para imponer a las partes la solución del conflicto en virtud de una decisión autónoma e innovadora. (Márquez, 2008, p. $67)$.

En derecho laboral mexicano, tiene años utilizando los medios de solución de controversias a través de la conciliación, previo y durante los juicios. Hace falta trabajar más en ellos y el acercar la justicia a los trabajadores, trabajando en erradicar los obstáculos que impiden que los trabajadores reclamen sus derechos, 
sin embargo, no hay que dejar de lado que, durante este tiempo, ha demostrado que la conciliación es efectiva para terminar con los conflictos entre empleado y empleador. De aquí que debemos trabajar para que todos los conflictos susceptibles de solucionar con conciliación, mediación, negociación o arbitraje se hagan con estos métodos y como primera instancia, quedando no como salida alterna, que es como se manejan dentro del mundo jurídico.

Para Márquez y de Villa (2013), los medios Alternos:

El tiempo ha demostrado que la mediación ha ido consolidándose, en proyectos sin duda exitosos, porque el equipo de promotores de la paz sigue creciendo a lo largo y ancho del país, con la convicción de que la mediación es una nueva profesión basada en la vocación de servicio hacia el prójimo y de que es un instrumento de paz (p.1591).

Es así como se pueda contar con una alternativa para la solución de los conflictos laborales generados por la negativa del pago de liquidación o finiquito al finalizar la relación laboral, en los municipios que abarca la competencia de la Procuraduría y sin que el trabajador salga de su lugar de residencia, evitando el gasto y el tiempo que implica un juicio.

Para los asuntos del orden civil, familiar, mercantil o penal, será de gran importancia también no solo enseñar a los profesionistas interesados en materia de medios de solución de controversias, sino también a los mentores que los guíen, porque de nada servirá tener excelentes prestadores del servicio de mediación cuando el mismo profesionista que lo instruyó, por cuestiones de ego, se resista a una solución no judicial para demostrar que sabe más o que puede más que el que fue su pupilo. Parra (2014) comenta que

El aula es el espacio de aprendizaje que le brinda la oportunidad a cada estudiante de incorporar nuevos conocimientos y experiencias. Además, es un escenario de interacción para la función socializadora. El alumno aprende en la medida que el docente de aula, en su rol de mediador, promueve el aprendizaje significativo, a partir de experiencias de reflexión y aplicación de estrategias que le permitan la 
construcción del aprendizaje (p.178).

La paz se logrará dialogando y alcanzando la justicia por voluntad y mérito propio, resolviendo los conflictos personales con acuerdos basados en el bienestar propio y el de la otra parte. Llevar a la práctica esta construcción de paz sin llegar a los juzgados será fundamental desde la enseñanza profesional. En la carrera de abogado, enseñan a ganar juicios, a empaparte de leyes, de pruebas y de todo lo necesario para contender y ganar, es desde las aulas que debemos enseñar a resolver problemas en vez de sembrar la idea de competir y ganar, ya que en muchas ocasiones lo que las personas necesitan no es una sentencia o dinero, sino un "perdón” de su contraparte. La adición de materias enfocadas en la sociología y psicología serán vitales para un abogado que va a tener formación como mediador o conciliador, logrando entender desde el lenguaje corporal, actitudes o emociones de las personas (programación neurolingüística), cuáles serán las técnicas para dar a cada uno lo que busca. Así, el abogado que memoriza leyes, procesos, formalismos, el que pondera derechos, dejará ser solamente un técnico jurídico y comprenderá las razones y por ende las soluciones a los problemas.

Arboleda considera sobre la importancia de transmitir una formación inclinada por las soluciones no judiciales y con un sentido que inhiba la contienda

"Hay que señalar la poca difusión de estos en las facultades de Derecho del país. Encontrando incluso que en algunas Universidades se estiman estos temas como asignaturas electivas o de segunda importancia, otorgándole preferencia a la formación tradicional y/o con una inclinación a la formación litigiosa, memorizando códigos y leyes" (Arboleda, 2017, p.83).

De los resultados de las encuestas aplicadas se encontró que los principales asuntos fueron despidos, negativa de pago de finiquito y accidente de trabajo, asuntos que en principio no deberían llegar a las procuradurías atendiendo al principio de cultura de paz y cultura de legalidad por los actores (trabajador y empleador), además, una vez que los asuntos llegan a la Procuraduría y el trabajador se encuentra con la opacidad en las asesorías, procesos y diligencias, demora y tardanza en 
entre citatorios, audiencias, resoluciones, etcétera, entonces, con esto se violan los principios constitucionales de acceso a la justicia sin ninguna restricción.

\section{5.- CONCLUSIONES}

Mientras exista una sociedad, existirá el conflicto, por lo que lejos de considerarlos como la pieza que se debe borrar en los grupos sociales, deben considerarse como la fuente donde se generan acuerdos. El derecho nace precisamente de los conflictos. Las partes en desacuerdo no han de verse como dos personas que se estorban y que por tanto deban enfrentarse y para que finalmente uno de ellos ceda frente el derecho del otro.

Deberá analizarse si la aplicación de los medios alternos de solución de conflictos es la adecuada en los órganos jurisdiccionales y si la misma autoridad que la realiza, sea la misma la que lleve el procedimiento que finalice en sentencia, no solo porque conocería de forma distinta la manera en que las partes ven el problema y podría generarse empatía por alguna de ellas, lo que haría caer a la autoridad en caer en distracción de su función. En los juzgados civiles de Ciudad Guzmán, Jalisco, es el mismo secretario de acuerdos quien previo a continuar con el procedimiento, lleva a cabo la cita conciliatoria de las partes, donde si bien es cierto la finalidad es la correcta, el que se realice la audiencia en su oficina, donde se encuentra su auxiliar, donde no se tiene la infraestructura adecuada y hay más expedientes sobre la mesa del trabajo pendiente, trabajando a puerta abierta para que otros abogados ingresan a revisar los libros, a hacer preguntas, contraviene lo que la doctrina establece para que pueda ser eficiente un procedimiento alternativo.

Los Métodos de Solución de Conflictos han dado resultado, deben considerarse no como alternativa para terminar juicios, sino como la primera instancia para resolverlos sin necesidad de iniciar aquél. Sin embargo, hay que pulir no solo a las instituciones sino también a quienes participan en él, con la finalidad de armonizar todos los elementos para que funcionen de una mejor manera. Se puede tener a un excelente mediador dentro de los Juzgados, pero si la sesión se lleva a cabo en un escritorio lleno de expedientes, sillas viejas que no están estables y el entrar y 
salir de abogados y otros servidores públicos, afectará completamente el resultado esperado. Por otro lado, se debe enfatizar en la preparación de los prestadores, en la neutralidad e imparcialidad que promueve este tipo de soluciones a conflictos, para que en conjunto con todo lo que significa realizar una buena mediación o conciliación, se logre solucionar los conflictos en el menor tiempo, con la menor molestia de los participantes y por lo tanto con menos consecuencias negativas en su vida cotidiana o su economía.

\section{REFERENCIAS}

Ackerman, M. (2007. El trabajo, los trabajadores y el derecho del trabajo. Revista de trabajo. V73, N. 3. p. 50-78. Recuperado de: https://juslaboris.tst.jus.br/ handle/20.500.12178/2378

Arboleda, A.P. (2017). Conciliación, mediación y emociones: Una mirada para la solución de los conflictos de familia. Civilizar. Ciencias Sociales y Humanas. V. 17, N.33, pp. 81-96. Recuperado de: https://www.redalyc.org/articulo. oa? id $=100254730005$

Bonilla, M.(2017). Memoria del IV Congreso Nacional de Derecho Constitucional. Tribunales, Territorio y Acceso a la Justicia. En Valadés D., Gutiérrez R. (Ed.). Ciudad de México (México): Instituto de Investigaciones Jurídicas.

Canessa, M. (2009). Los derechos humanos laborales en el Derecho Internacional. Derecho PUCP, (63). Pp. 349-373. Disponible en: http://revistas.pucp.edu. pe/index.php/derechopucp/article/view/2984

Cámara de Diputados del H. Congreso de la Unión. (1, abril, 1970). Artículo 530 [Título Noveno]. Ley Federal del Trabajo. http://www.diputados.gob.mx/ LeyesBiblio/pdf/125_020719.pdf

Casal, J. (2008). Los Derechos Humanos y su protección. Estudios sobre derechos humanos y derechos fundamentales. Caracas (Venezuela): Universidad Católica Andrés Bello. 
Castillo, C. \& Bautista, M. (2018). Acceso a la Justicia Alternativa: Un Reto Complejo. Utopía y Praxis Latinoamericana. 23, (2). https://www.redalyc. org/jatsRepo/279/27957770012/27957770012.pdf

Constitución Política de los Estados Unidos Mexicanos [Const.] (1917). http:// www.diputados.gob.mx/LeyesBiblio/pdf/1_090819.pdf

Cossío, J. R. (Ed.). (2017). Constitución Política de los Estados Unidos Mexicanos Comentada III. Ciudad de México (México): Editorial Tirant Lo Blanch México.

De Villa, J. C. (2012). La mediación en Guanajuato. Acta Universitaria. 22 (2), 19-23. https://www.redalyc.org/articulo.oa?id=41623191003

García, L. (2007). La mediación familiar: una aproximación normativa. IUS. Revista del Instituto de Ciencias Jurídicas de Puebla A.C., 20, 78-96. https:// www.redalyc.org/articulo.oa?id=293222932005

Goldin, A. (2010). Los derechos sociales en el marco de las reformas laborales en América Latina. Relaciones laborales: Revista crítica de teoría y práctica. 2, 1311-1344. https://dialnet.unirioja.es/servlet/articulo?codigo=3250316

Ibarra, R. (2004). La administración de justicia laboral federal en México. Distrito Federal, (México): Porrúa.

La Rosa Calle, J. (2008). La jurisdicción alternativa como mecanismo de acceso a la justicia. URVIO, Revista Latinoamericana de Estudios de Seguridad, 3, 104109. en: https://revistas.flacsoandes.edu.ec/urvio/article/view/104-109/1649

Los rezagos en justicia laboral (25 de marzo de 2017). El Universal. http://vlex. com/vid/rezagos-justicia-laboral-672101161

Maraniello, P. (2008). Las limitaciones económicas al acceso a la justicia. IUS. Revista del Instituto de Ciencias Jurídicas de Puebla A.C. 21, 98-118. http:// www.redalyc.org/articulo.oa? $\mathrm{id}=293222942007$ 
Márquez, A. E. (2008). La conciliación como mecanismo de justicia restaurativa. Prolegómenos. Derechos y Valores, XI (22), 57-74. https://www.redalyc.org/ pdf/876/87602205.pdf

Marquez, M. G. \& De Villa, J. C. (2013). Medios alternos de solución de conflictos. Biblioteca jurídica virtual del instituto de investigaciones jurídicas de la UNAM. https://archivos.juridicas.unam.mx/www/bjv/libros/8/3568/15. pdf

Minuta Proyecto de Decreto por el que se reforman, adicionan y derogan diversas disposiciones de la Ley Federal del Trabajo. Cámara de Diputados del Congreso de la Unión, Ciudad de México, 19 de abril de 2019.

Natividad, T. H. (2015). La justicia laboral mexicana ante los derechos humanos y la competitividad. Biblioteca jurídica virtual del instituto de investigaciones jurídicas de la UNAM. https://bliblio.juridicas.unam.mx/

Ovalle, J. (1996). Garantías Constitucionales del Proceso. Distrito Federal (México): Oxford University Press.

Padrón, M. (2018). Apuntes introductorios para (re)pensar los estudios sobre mercados laborales desde el enfoque de derechos. Una aproximación desde el caso mexicano. En Padrón M., D’Angelo N., Mancini F. y Gandini L. (Ed.), Trabajo y derechos en México nuevas afectaciones a la ciudadanía laboral. (pp.1-34). Ciudad de México, México: Instituto de Investigaciones Jurídicas.

Parra, K. N. (2014). El docente y el uso de la mediación en los procesos de enseñanza y aprendizaje. Revista de Investigación, 38 (83), 155-180. https:// www.redalyc.org/articulo.oa?id=376140398009

Ruiz, V. (2014). Democracia y derechos humanos en México. Situación actual. Comisión de Derechos Humanos del Estado de México. México. https://www. codhem.org.mx/LocalUser/codhem.org/difus/democracia.pdf 
Segundo Tribunal Colegiado en materia Civil del Tercer Circuito. (Octubre 2013). Acceso a los mecanismos alternativos de solución de controversias, como derecho humano. Goza de la misma dignidad que el acceso a la jurisdicción del Estado.( Tesis aislada 2004630). https://sjf.scjn.gob.mx/

Velásquez, C. J. (2004). Conciliación de conflictos ambientales. Revista de Derecho, 21, 106-130. https://www.redalyc.org/articulo.oa?id=85102105 